\title{
Pensononowoor
}

2018 , vol. $80,12-23$

http://dx.doi.org/10.12657/denbio.080.002

\author{
Silvia Traversari", Giovanni Emiliani", Maria Laura Traversi, \\ Monica Anichini, Alessio Giovannelli*
}

\section{Pattern of carbohydrate changes in maturing xylem and phloem during growth to dormancy transition phase in Picea abies (L.) Karst.}

\author{
Received: 9 February 2018; Accepted: 10 July 2018
}

\begin{abstract}
Wood production is a metabolic process requiring high amount of soluble carbohydrates as source of carbon skeletons, energy, or signalling molecules. Nevertheless, the role of soluble sugars and starch has been rarely investigated in the growth to dormancy transition phase. The aim of this work was to investigate the carbohydrate concentrations and the transcription level of some candidate genes involved in cellulose and starch metabolisms in competitive carbon sinks such as phloem, maturing xylem, and xylem during the active growth to dormancy transition phase in Picea abies (L.) Karst. Stems were sampled every two weeks between July and October from potted eight-year-old Norway spruce plants. Results highlight that the cellulose biosynthesis regulated the pattern of carbohydrate changes in the phloem and maturing xylem during the transition to dormancy. In particular, the cessation of CesA ( $\alpha$-cellulose synthase) mRNA accumulation in maturing xylem determined a shift in the carbohydrate partitioning from the utilization sinks to the storage compartment. The content of carbohydrates was modulated in the maturing xylem by cellulose metabolism during the xylogenesis and by starch metabolism during the cambium dormancy. On the contrary, the carbon competition between utilization and storage sinks seemed to be less connected within the phloem. Since the amount of soluble carbohydrates within the maturing xylem and phloem has never been limited during the growth to dormancy transition phase, the cessation of the CesA transcription was probably determined by environmental conditions rather than by carbon limitation or sink competition.
\end{abstract}

Keywords: Cell wall biosynthesis, latewood, starch, sugars, wood formation, wood quality

Addresses: S. Traversari, G. Emiliani, M. L. Traversi, M. Anichini, A. Giovannelli, Trees and Timber Institute (IVALSA-CNR), Via Madonna del Piano 10, 50019, Sesto F.no (Florence), Italy, e-mail: giovannelli@ivalsa.cnr.it

S. Traversari, Institute of Life Sciences, Sant'Anna School of Advanced Studies, Piazza Martiri della Libertà 33, 56127, Pisa, Italy (present address)

"Equal contribution

The authors declare no conflicts of interests

\section{Introduction}

Trees maintain a positive carbon balance to support their growth despite the continuous exposure to environmental stresses. In plants, carbon partitioning, that is the carbon distribution from sources to sinks or storage compartments, is influenced by the capacity to take up carbon and to translocate it toward other organs (Wardlaw, 1990). Since more than two-thirds of woody plant dry weight is 
represented by transformed sugars, the metabolism of carbohydrates, their transport from photosynthetically active source organs to photosynthetically inactive sink organs, and their incorporation within new tissues are fundamental processes (Dickson, 1989). Sinks are divided in two types: storage sinks, like wood parenchyma or seeds, and utilization sinks, highly metabolically active and rapidly growing tissues and organs such as cambial region or developing leaves (Sonnewald \& Willmitzer, 1992).

Within the stem of woody plants, starch is the main storage carbohydrate. It is synthesised and mobilised during the day and its content changes within the stem according with a defined seasonal pattern as well as in response to environmental stresses (Regier et al., 2010). Several key enzymes are involved in the regulation of starch turnover such as the starch synthases (SS), the amylases, such as $\beta$-amylases (Bmy), or the ADP glucose pyrophosphorylases, and their functions and interactions have been already elucidated in model plants such as Arabidopsis thaliana (Stitt \& Zeeman, 2012) as well as in stem of woody plants like poplar and black locust (Witt \& Sauter, 1994; Magel et al., 1997). The carbohydrate balance in the storage and utilization sinks is mainly regulated by the $\mathrm{C}$-sink strength of growing and developing tissues which in turn depends on the season and the plant phenology. Therefore, the carbohydrate reserves fluctuate throughout the year decreasing rapidly with bud break, root growth, and the onset of cambial activity, and then increasing at the end of growing season in correspondence to dormancy (Loescher et al., 1990; Regier et al., 2010). The intra-annual fluctuations of stored and mobile carbohydrates into the stem are mainly regulated by the C-requirements of cambium and developing xylem and phloem (Hoch et al., 2003; Deslauriers et al., 2009) and they are strictly associated with the cambium phenology (Gruber et al., 2013; Jyske et al., 2015). Recent evidence showed in Larix decidua Mill. and Picea abies (L.) Karst that the concentration of soluble sugars in cambial region is higher in concomitance with the secondary wall formation and the lignification than during the cell proliferation peak (Simard et al., 2013). Cell wall deposition and lignification are metabolic processes requiring high amounts of soluble carbohydrates as source of carbon skeletons, energy, or signalling molecules (Giovannelli et al., 2011). Lignification is the process by which monolignols are linked together to form a complex racemic aromatic heteropolymer (Boerjan et al., 2006). The deposition of lignin within the cellulose matrix is the final process that leads to a mature tracheid and it occurs in concomitance with the cell death (Rathgeber et al., 2016). This metabolic process occurs differently during the formation of earlywood and latewood tracheids (Antonova et al., 2014) and in latewood tracheids it lasts beyond the end of cambium proliferation and cell expansion phase (Gindl et al., 2000). In Picea abies (L.) Karst, the latewood tracheids have smaller diameters and thicker secondary walls than the earlywood ones and the transition between the two tracheid types takes place gradually in concomitance with the decline of photoperiod and temperature (Castagneri et al., 2017). Since the latewood fraction can explain up to $60 \%$ of the density variation of woody rings, it represents the main trait to predict the wood quality (Wimmer, 1995). Furthermore, the maximal latewood density can be used as a proxy-climatic indicator into tree rings (Björklund et al., 2017).

Although many studies have been carried out to understand the physiological mechanisms involved in carbon partitioning in the stem during the onset of cambium activity (Begum et al., 2010; Regier et al., 2010; Simard et al., 2013), the role of soluble sugars and starch in latewood formation and dormancy transition has rarely been investigated (Uggla et al., 2001; Antonova et al., 2006; Deslauriers et al., 2009). The understanding of mechanisms involved in the control of carbohydrate partitioning from sources to sinks represents a key step to clarify the whole plant-carbon balance (Sharkey, 2015). Some authors reported that several genes related to carbon metabolism could affect the carbon partitioning in the stem of poplar (Coleman et al., 2009), cotton (Babb et al., 2001), and Scots pine (Uggla et al., 2001). For example, sucrose synthase (Sus), connected to the complex of plasma-membrane cellulose synthase (CesA) has a pivotal role in conveying UDP-Glucose into cellulose production (Coleman et al., 2006; Ruan, 2014). Geisler-Lee et al. (2006) reported a low expression of genes related to the starch metabolism in xylem-forming tissues of $P$. trichocarpa, demonstrating that sucrose was entirely used for cell wall formation or as energy source rather than stored as starch. However, Oribe et al. (2003) showed that the cell differentiation in Abies sachalinensis Schmidt. depended on the continuous supply of sucrose derived from the hydrolysis of stored starch within the stem during cambial reactivation. These results highlight the importance of deepening the knowledge of the role of the cellulose and starch metabolisms for understanding the distribution of the non-structural carbohydrates along the xylem-phloem radial profile of the stem. The definition of the main role of these mechanisms in the carbon partitioning within the stem could represent a key step to understand the involvement of carbohydrate metabolism in latewood formation in Norway spruce.

In a previous paper, Emiliani et al. (2011) showed that: $i)$ the molecular processes involved in monolignol biosynthesis are not restricted to the cambial activity timeframe but continue after the end of 
cambium proliferation; ii) the phloem could play a crucial role in the monolignol biosynthesis process acting as a reservoir of monolignol precursors necessary to complete the latewood tracheid lignification. According with other reports, source C-limitation was not found during growing season and dormancy in cambial region of Norway spruce at high elevation sites (Simard et al., 2013). Although these results highlight the putative pivotal role of cambium in the carbon partitioning within the stem, very little information has been reported about the carbon status within surrounding tissues such as ray parenchyma, maturing xylem, and phloem during the growing season and dormancy. In this frame, an important question remains to be solved: could the high C-sink strength of cambium induce a $\mathrm{C}$-depletion within the surrounding living tissues and wood during period of reduced C-source activity (low photosynthetic rate) and high C- requirement for lignification? Since the $\mathrm{C}$-storage tissues are considered active sinks competing with growth (Sala et al., 2012), the final phase of cell wall deposition and lignification could compete with the storage sinks, such as ray parenchyma and mature phloem, during the transition to dormancy. On the basis of these assumptions, we hypothesised that: a) the concentration of non-structural carbohydrates within competing C-sinks along the $\mathrm{xy}$ lem-phloem radial profile was regulated by cambium activity; b) the cellulose biosynthesis was the main metabolic process determining the fate of soluble carbohydrates into the stem during the transition to dormancy. In this frame, the aim of this work was to investigate the concentration of carbohydrates and the transcription level of some candidate genes involved in cellulose and starch metabolisms in the phloem $(\mathrm{Ph})$, maturing xylem (MXy), and mature xylem (Xy) during the active growth to dormancy transition phase in Picea abies (L.) Karst.

\section{Materials and methods}

\section{Plant material}

In October 2007, fifty six-year-old Norway spruce (Picea abies (L.) Karst) plants, selected from open-pollinated trees, were potted in plastic pots (45 l) filled with a mixture of sand, peat moss, and clay (55/40/5 $\mathrm{v} / \mathrm{v} / \mathrm{v}, \mathrm{pH}=6.8$ ) and grown in the nursery of the Az. Demaniale Rincine (Florence, Italy, altitude 900 $\mathrm{m}$ a.s.l). In early January 2009 , forty plants were selected for their uniformity (average collar diameter and height $4.6 \pm 0.2 \mathrm{~cm}$ and $128 \pm 6.2 \mathrm{~cm}$, respectively) and transferred to a nursery of CNR-IVALSA, Sesto Fiorentino (Florence, Italy). The plants were fertilized with a commercial slow-release fertilizer (18:18:18, N:P:K) and irrigated daily using a system with two drip nozzles for each plant $\left(2 \mathrm{l} \mathrm{h}^{-1}\right.$ each dripper) in order to maintain the soil moisture at field capacity from April to October. On Day Of Year (DOY) 133, plants were divided randomly in three groups: a) twelve plants were used to asses wood formation by microcore puncher; $b$ ) twenty plants were used for destructive sampling to assess biochemical and molecular analyses from DOY 210 to DOY 289, as it has already reported in Emiliani et al. (2011); c) eight supplementary plants were used to monitor stem radial growth with point dendrometers (data reported in Emiliani et al., 2011). In this work we used only data deriving from plants of points $a$ and $b$.

\section{Wood formation phenology}

The tracheid formation process was investigated by performing anatomical analyses on wood microcores. The twelve plants (group a) used for anatomical observations were randomly divided in four groups of three plants each. Microcores were collected every two weeks from four plants using a Trephor tool. A microcore from each plant $(1.8 \mathrm{~mm}$ in diameter and $15 \mathrm{~mm}$ length), comprising bark, cambial zone and, at least, the last formed tree-ring was collected. For each sampling day, one plant for each group $(n=4)$ was used. Thus, at the end of experiment each plant has been sampled four times. Immediately after the sampling, the microcores were preserved in a solution $10 / 90 \mathrm{v} / \mathrm{v}$ of $\mathrm{H}_{2} \mathrm{O} / \mathrm{EtOH}$. The woody samples were embedded in ice on a Peltier plate, and transverse sections of $8-12 \mu \mathrm{m}$ thickness were obtained using a sliding microtome. The wood sections were stained with cresyl violet acetate $\left(0.16 \%\right.$ in $\left.\mathrm{H}_{2} \mathrm{O}\right)$ and examined within 10-25 min using visible and polarized lights to discriminate the differentiation of xylem according to four distinct phases (cambium division, cell radial enlargement, secondary wall thickening and lignification, and mature tracheids). A Nikon Eclipse E800 light microscope connected to a Nikon DS-Fi2 microscope camera (Nikon Corporation, Tokyo, Japan) was used for anatomical observations. Transversal sections were analysed on four to six independent images per sector using the NIKON NIS-ELEMENTS software. For each section, the radial number of cambial $\left(\mathrm{n}_{\mathrm{C}}\right)$, enlarging $\left(\mathrm{n}_{\mathrm{E}}\right)$, wall thickening $\left(\mathrm{n}_{\mathrm{w}}\right)$, and mature $\left(\mathrm{n}_{\mathrm{M}}\right)$ cells were counted along three radial files. In the cambial zone, the cells were selected on the basis of their thin cell walls and small radial width (Balducci et al., 2016). The enlarging cells were selected for their greater radial dimensions and the presence of a thin primary wall. The cells in the wall thickening zone were selected on the basis of their birefringence under polarized light (which indicated the presence of secondary cell wall) and their colour (the reaction of cresyl violet acetate with lignin produced a colour change from violet to 
blue when lignification was complete). Finally, the cells with homogeneous blue colour over the whole cell wall were considered mature.

\section{Sample preparation for biochemical and molecular analyses}

For the biochemical and molecular analyses, a total of twelve plants were harvested every two weeks, from DOY 210 to DOY 289, at the same hour in the early morning as reported by Emiliani et al. (2011). Plants were harvested on DOY 210 (28 ${ }^{\text {th }}$ July), 224

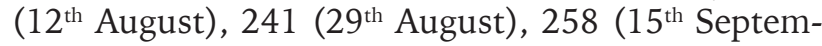
ber), 274 ( $1^{\text {st }}$ October), and DOY 289 (16 ${ }^{\text {th }}$ October). Two stem discs $(2 \mathrm{~cm}$ thick) were collected from the lower section of the stem (one-fourth of the height from the collar) and immediately frozen in liquid nitrogen.

Stem discs were freeze-dried at a constant temperature of $-50^{\circ} \mathrm{C}$ under vacuum. The outer part of the bark was removed, and the cambial zone with the inner phloem $(\mathrm{Ph})$ and the maturing xylem (MXy) was gently scraped with a razor blade from the inner side of the bark and the outermost side of the stem, respectively. On average 50 to $80 \mathrm{mg} \mathrm{g}^{-1} \mathrm{DW}$ of MXy and $180-300 \mathrm{mg} \mathrm{g}^{-1} \mathrm{DW}$ of $\mathrm{Ph}$ were collected at each sampling date. The mature xylem (Xy), corresponding to the new formed xylem, was reduced to a fine powder with Ultra Centrifugal mill ZM 200 (Retsch, Haan, Germany) equipped with a 12-tooth rotor and ring sieves with 0.75 and $0.25 \mathrm{~mm}$ trapezoid holes.

\section{Soluble sugar and starch quantifications}

Soluble sugar and starch quantifications were performed on $40 \mathrm{mg}$ of freeze-dried powder ( $\mathrm{Ph}, \mathrm{MXy}$, and $\mathrm{Xy}$ ) following the protocol reported in Giovannelli et al. (2011). The content of soluble sugars was determined by a HPLC (high-performance liquid chromatography) equipped with a SHODEX SUGAR Series SC-1011 $8 \times 300 \mathrm{~mm}$ column (Showa Denko, Germany) preceded by a pre-column Sugar Pak II Guard-Pak Insert (Waters). The mobile phase was $\mathrm{H}_{2} \mathrm{O}$ (Milli Q grade, $\mathrm{pH}=7$ ), with a flow rate of 0.5 $\mathrm{ml} \mathrm{min}^{-1}$. Soluble sugars were identified with a refractive index detector (LC-30 RI, Perkin Elmer). The identification of soluble sugars was verified using carbohydrate standards (Sigma-Aldrich, St. Louis, MO, USA) and normalized by means of the sorbitol added as internal standard solution (Harris, 1997). The starch was measured in the residual powder after the soluble sugars extraction. Briefly, the powder was suspended in $1.5 \mathrm{ml}$ acetate buffer $(\mathrm{pH}=5)$, boiled at $100^{\circ} \mathrm{C}$ for $1 \mathrm{~h}$ and cooled at room temperature. Thus, samples were incubated at $55^{\circ} \mathrm{C}$ for 16 $\mathrm{h}$ with $150 \mu \mathrm{l}$ of Amyloglucosidase from Aspergillus niger (Fluka, Sigma-Aldrich, St. Louis, MO, USA). Finally, samples were diluted with distilled water to 5 $\mathrm{ml}$ and three aliquots of each sample $(0.25 \mathrm{ml})$ were assayed colorimetrically using PGO Enzyme Preparation and o-Dianisidine (Sigma-Aldrich, St. Louis, MO, USA). The detection limit of this protocol was $0.1 \mathrm{mg}$ of glucose equivalent.

\section{Primer design, RNA isolation, and RT- PCR analyses}

Total RNA was extracted from $40 \mathrm{mg}$ of freezedried powder ( $\mathrm{Ph}$ and $\mathrm{MXy}$ ) according to Chang et al. (1993), substituting spermidine with $\beta$-mercaptoethanol in the extraction buffer. Nucleic acid concentration was determined using a NanoDrop ND100 spectrophotometer (Termo Fisher Scientific, Waltham, MA, USA). RNA integrity was checked by denaturing agarose gel electrophoresis. Total RNA was treated with "DNase I Amplification Grade" kit (Invitrogen, Thermo Fisher Scientific, Waltham, MA, USA) following the manufacturer's protocol, precipitated with $\mathrm{LiCl}$ and re-suspended in $\mathrm{H}_{2} \mathrm{O}$ (Milli Q grade). An amount of $1 \mu \mathrm{g}$ of total RNA was retro-transcribed in first-strand complementary DNA (cDNA) using the reverse transcription polymerase chain reaction system "SuperScript VILO" MasterMix" (Invitrogen, Thermo Fisher Scientific, Waltham, MA, USA) according to the manufacturer's protocol. The transcript accumulation of 4 genes involved in carbon metabolism was analysed with RT-PCR (Chromo 4 Real Time System, MJ Research, Waltham, MA, USA). Two reference genes, EF1- $\alpha$ and $18 \mathrm{~S}$, were chosen as references for normalization as reported by Emiliani et al. (2011). The mRNA transcript accumulations of the following genes were analysed: sucrose synthase (Sus), $\alpha$-cellulose synthase (CesA), starch synthase (SS), and $\beta$-amylase (Bmy). For each multigene family, one member was chosen on the basis of Arabidopsis thaliana homologue. The A. thaliana homologue amino acid sequences of these enzymes were retrieved from TAIR database (www. arabidopsis.org - Huala et al., 2001) and used as seeds for a BLAST search against the $P$. abies proteome in the Congenie database (http://congenie.org/ Nystedt et al., 2013). The sequences retrieved from Congenie database were used to design primers (Tab. S1 in Supplementary Material). Sus primers were designed on CDS of MA_10432094g0010, which was homologue with AT4G02280 TAIR database amino acid sequence (SUS3 protein). CesA primers were designed on CDS of MA_183130g0010, which was homologue with AT5G17420 TAIR database amino acid sequence (CESA7 protein). SS primers were designed on CDS of MA_294189g0010, which was homologue with AT3G01180 TAIR database amino 
acid sequence (SS2 protein). Bmy primers were designed on CDS of MA_10432630g0020, which was homologue with AT3G23920 TAIR database amino acid sequence (BMY7 protein). The quantification cycles (Cqs) of all cDNA samples were used to calculate the target and reference gene specific amplification efficiencies. The PCRs were performed in duplicate reactions for each sample. In each run, and for each gene, a no template control was amplified, resulting in Cqs that were always higher than 38. The PCRs were performed using the "Express SYBR greener qPCR Supermix Universal" kit (Invitrogen, Thermo Fisher Scientific, Waltham, MA, USA) according to the manufacturer's protocol. The complete RT-PCR protocol was $95^{\circ} \mathrm{C}$ for $20 \mathrm{~s}, 60^{\circ} \mathrm{C}$ for $30 \mathrm{~s}$, and $72^{\circ} \mathrm{C}$ for $30 \mathrm{~s}$ for a total of 40 amplification cycles. The RTPCR results were then analysed with qBase software using the $\Delta \Delta \mathrm{Cq}$ method with the reference genes.

\section{Statistical analyses}

All the data were checked for normal distribution using D'Agostino-Pearson $\mathrm{K}^{2}$ test and transformed when necessary before conducting analysis of variance (ANOVA). The effects of the time and the interaction between time and tissue were assessed using one-way or two-way ANOVA, respectively. Post hoc analysis was conducted using Bonferroni multiple comparison test $(P<0.05)$ or Tukey-Kramer test $(P<0.05)$, respectively. Correlation was verified by Pearson's test. All the analyses were performed with NCSS Data Analysis software and all graphs were plotted with Prism 5 (GraphPad, La Jolla, CA, USA).

\section{Results}

\section{Phenology of wood formation}

In order to characterize the cambium growth to dormancy transition phase, the phenology of tracheid formation was followed by anatomical observations from DOY 120 (growth) to DOY 289 (dormancy). On the basis of the number of cell types assigned to a well-defined developmental stage (obtained by the weekly microcore sampling), we selected six key steps (Fig. 1): $1^{\circ}$ ) culmination in the number of cells in cambial region and enlarging phase (from DOY 148 to DOY 210$) ; 2^{\circ}$ ) decrease in the number of enlarging cells (from DOY 210 to DOY 224); $3^{\circ}$ ) reduction in the number of cells within the cambial zone (from DOY 224 to DOY 241$) ; 4^{\circ}$ ) cessation of cell proliferation, absence of enlarging cells and high number of cells reaching the wall thickening phase (from DOY 241 to DOY 258); $5^{\circ}$ ) end of cell wall thickening (from DOY 258 to DOY 274); $6^{\circ}$ ) end of cell morphology modifications (from DOY 274 to DOY 289). On DOY 210,

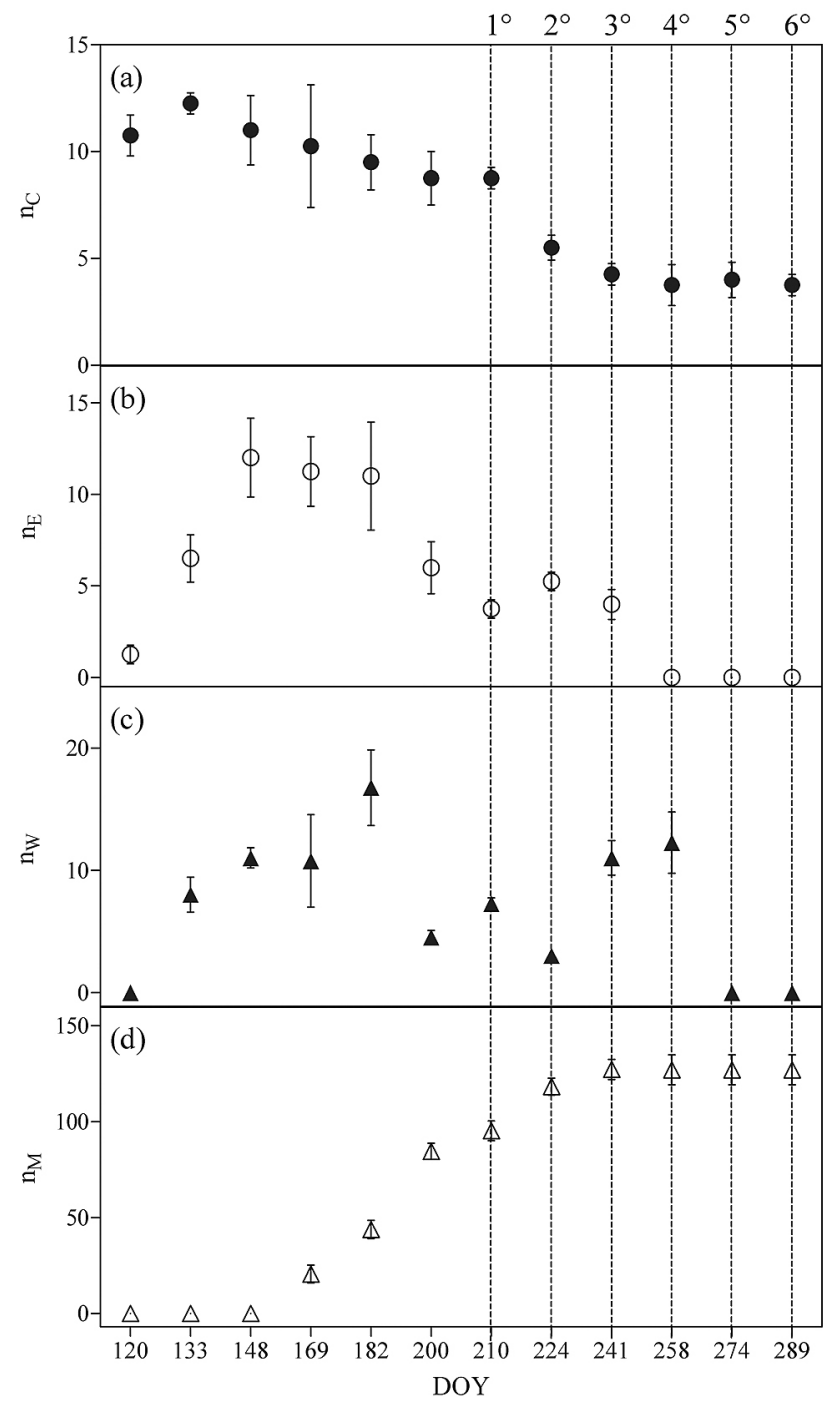

Fig. 1. Phenology of wood formation in Picea abies (L.) Karst stem during the growing season and the transition to dormant phase. Radial number $( \pm S D, n=4)$ of cambial $\left(n_{C}\right)$, enlargement $\left(n_{E}\right)$, wall thickening $\left(n_{W}\right)$, and mature $\left(n_{M}\right)$ cells were counted under visible and polarized lights at 400-500 $\times$ magnification after staining with cresyl violet acetate. Dashed lines represent the sampling dates of stem samples for the biochemical and molecular analyses $\left(1^{\circ}, 2^{\circ}, 3^{\circ}, 4^{\circ}, 5^{\circ}\right.$, and $6^{\circ}$ sampling date)

more than $75 \%$ of mature tracheids of the current woody ring were produced (Fig. 1d). At this time, the cambial zone was composed of 8-15 cells, 9-10 derivative xylem cells in expansion phase, and 8-9 cells in wall thickening phase (Fig. 1a-c). Rapid morphological changes in the cambial zone were recorded from DOY 210 to DOY 241. In this phase, both the number of cells in proliferation that in enlargement decreased thus determining the shrinkage of the cambial zone width (from $200 \mu \mathrm{m}$ on DOY 201 to $80 \mu \mathrm{m}$ on DOY 241, data reported in Emiliani et al., 2011). As a consequence, the duration of cell differentiation process increased (expressed as the time that a cell spent in each phase before it became mature) and a high 
number of cells were undergone to wall thickening and lignification (from DOY 241 to DOY 258). In this frame, the morphological traits of the newly formed tracheids did not change further and the deposition of secondary wall ended on DOY 274. From DOY 274 to DOY 289, cambium was dormant, cell morphology did not change, and lignification occurred only in latewood tracheids.

\section{Soluble sugars and starch concentrations}

The soluble sugar and starch contents were quantified during the six steps of transition from active growth to dormancy in the Ph, MXy, and Xy (Fig. 2, Fig. 3 and Fig. S1 in Supplementary Materials). The $\mathrm{Ph}$ and MXy had significantly higher soluble sugar
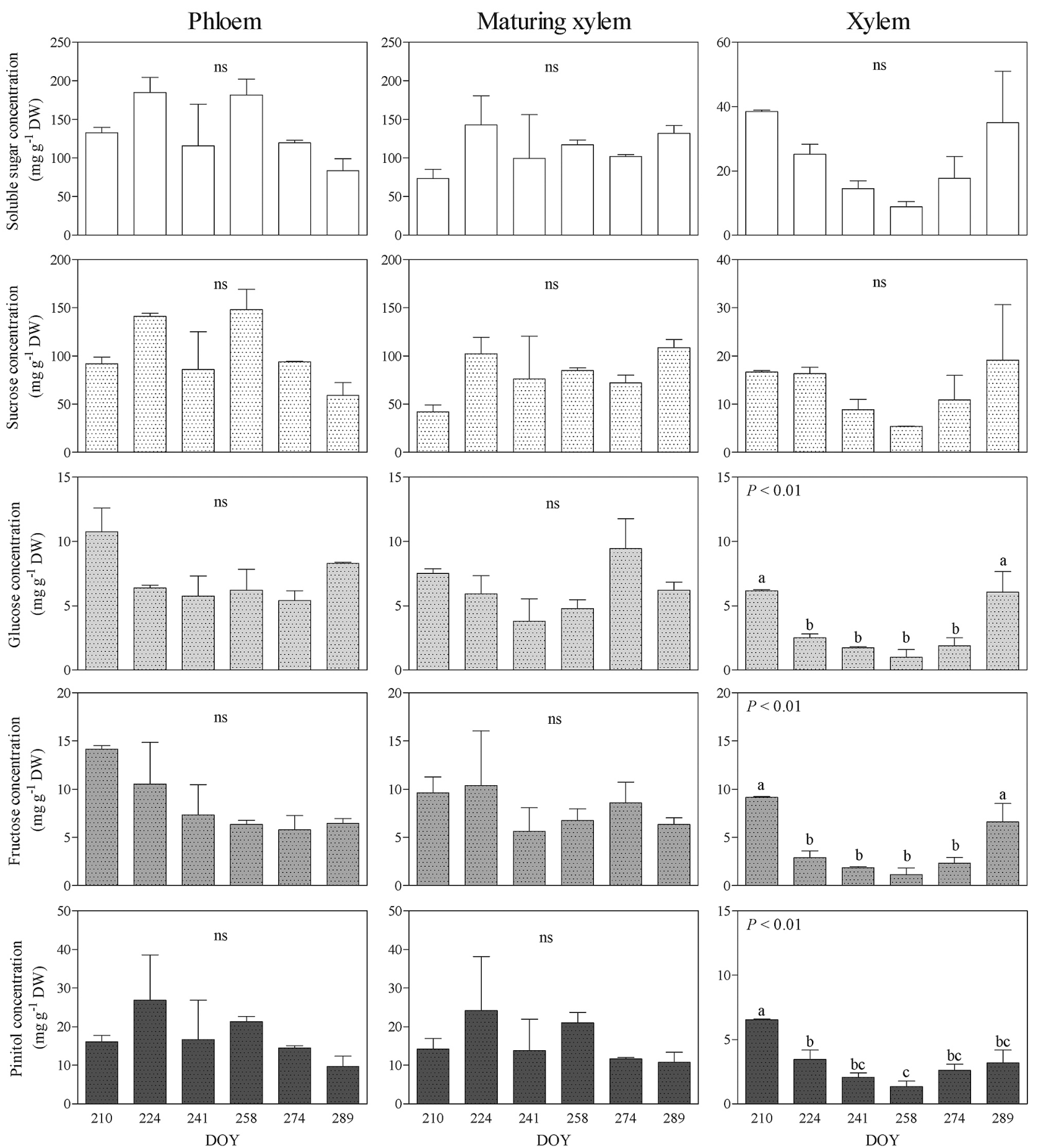

Fig. 2. Concentrations of total soluble sugars, sucrose, glucose, fructose, and pinitol within Ph, MXy, and Xy of Norway spruce stems. Bars represent the mean + SD. One-way ANOVA P-values and Bonferroni multiple comparison post hoc test results are reported in the figure 


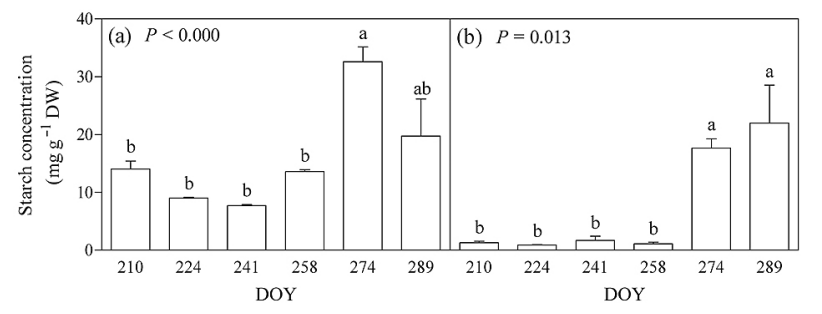

Fig. 3. Starch concentration in Ph (A) and MXy (B) during the growth to dormancy transition phase in Norway spruce stems. Bars represent the mean + SD. One-way ANOVA $P$-values and Bonferroni multiple comparison test results are reported in the figure. MXy data were $\log _{10}(\mathrm{x})$ transformed in before the analysis

concentrations than the Xy $(P<0.001)$ showing a lower C-sink strength of wood if compared to the living tissues. However, the total amount of soluble sugars in the $\mathrm{Ph}$ was higher than in the MXy $(P=$ 0.023). The difference in the amount of soluble sugars between the Ph and MXy induced the formation of a soluble carbohydrate gradient that reached the lowest value on DOY $241\left(\Delta_{\text {Ph-Mxy }}=20 \mathrm{mg} \mathrm{g}^{-1} \mathrm{DW}\right)$ in correspondence with the end of cambium proliferation and the decrease in cell expansion rate. On the contrary, the highest $\Delta_{\mathrm{Ph}-\mathrm{MXY}}\left(80 \mathrm{mg} \mathrm{g}^{-1} \mathrm{DW}\right)$ was reached on DOY 258 in correspondence with the lowest amount of soluble sugars in the Xy $\left(<10 \mathrm{mg} \mathrm{g}^{-1}\right.$ DW) and a high number of cells which have transited to wall thickening. The cessation of cambium proliferation and cell wall deposition (DOY 274-289) did not induce an accumulation of soluble sugars in the MXy. At all sampling times, sucrose was the major soluble sugar in the stem and it represented on average $74 \%$ and $70 \%$ of the total soluble sugars in the $\mathrm{Ph}$ and MXy, respectively. On the contrary, it decreased to $56 \%$ in the Xy. Pinitol was the most abundant polyol and it accounted on average for over $12 \%$ of the total soluble sugars while the hexoses (glucose and fructose) did not exceed the $7 \%$ in the $\mathrm{Ph}$ and MXy and $15 \%$ in the Xy. Raffinose was always present in traces in the $\mathrm{Ph}$ and MXy $(<2 \%$ of total soluble sugars) and it was not recorded in the Xy. Sucrose concentration did not statistically change during the transition from active growth to dormancy in all tissues showing that the disaccharide was not limiting during this stage. On the contrary, the amounts of pinitol and hexoses changed significantly in the Xy $(P<0.01)$, while they did not change in the $\mathrm{Ph}$ and $\mathrm{MXy}$. In particular, these soluble sugars reached a minimum in the Xy in concomitance with the end of cell enlargement phase (DOY 258).

Starch (Fig. 3) was only present in the $\mathrm{Ph}$ and MXy, while it was undetectable in the Xy; as a whole, the $\mathrm{Ph}$ had double amount of starch compared to the MXy (on average 16 vs $7 \mathrm{mg} \mathrm{g}^{-1} \mathrm{DW}, P=0.05$ ). However, a seasonal trend characterized the amount of starch in both tissues. In particular, from DOY 210 to
DOY 258 (from cambium proliferation to the end of cell enlargement), the starch content remained stable, ranging from 8 to $12 \mathrm{mg} \mathrm{g}^{-1} \mathrm{DW}$ in the $\mathrm{Ph}$ and 2-3 $\mathrm{mg} \mathrm{g}^{-1} \mathrm{DW}$ in the MXy. A significant increase in starch content was recorded between DOY 258 and DOY 274 in both tissues in correspondence with high cell wall deposition rate.

\section{mRNA transcriptional accumulation}

The mRNA accumulation (Fig. 4) was monitored in the $\mathrm{Ph}$ and MXy for the following genes: sucrose synthase 3 (Sus), $\alpha$-cellulose synthase 7 (CesA), $\beta$-amylase 7 (Bmy), and starch synthase 2 (SS). The transcript accumulation of the selected genes highlighted their involvement in the carbon metabolism during the transition from cambium growth to dormancy in Norway spruce stem. The CesA (Fig. 4a) transcription was strictly related to the cell wall deposition processes. In particular, CesA mRNA transcriptional accumulation was recorded until the cell wall thickening occurred in the derivative cambial cells and then it rapidly ceased. Specifically, the CesA mRNA accumulation showed different trends within the two tissues (time $\times$ tissue, $P<0.001$ ). Within the $\mathrm{Ph}, \mathrm{Ces} A$ gene was highly transcribed until DOY 224, and then the transcription rapidly decreased until reaching the detection limit after DOY 241. On the contrary, the mRNA accumulation showed a high variability in the MXy. However, the CesA mRNA accumulation increased until DOY 258 and then it dropped down at the detection limit. As for CesA, the Sus mRNA transcriptional accumulation (Fig. 4b) was affected by the cambium phenology. As a whole, the Sus mRNA accumulation differed during the latewood formation between tissues (time $\times$ tissue, $P=0.033$ ), showing that the Ph and MXy had different C-requirements or specific needs during the active growth to dormancy transition phase. In particular, Sus was more transcribed in the $\mathrm{Ph}$ on DOY 241 and 258, in correspondence with a high cell wall thickening rate. The Bmy mRNA accumulation (Fig. 4c) increased during the transition from cambium growth to dormancy and the trend differed between the Ph and MXy (time $\times$ tissue, $P<0.001$ ). Bmy mRNA transcription was higher in the Ph than in the MXy on DOY 210 and in correspondence with the highest rate of cell wall thickening (DOY 258 and DOY 274). The SS mRNA accumulation (Fig. 4d) increased during the cambium transition from activity to dormancy showing that this gene was mostly involved in C-storage rather than in cell differentiation and growth. The relative abundance of SS mRNA was significantly higher in the Ph than in the MXy during cambium proliferation and cell enlargement while no differences were recorded later DOY 224. The mRNA accumulation of genes involved in starch 

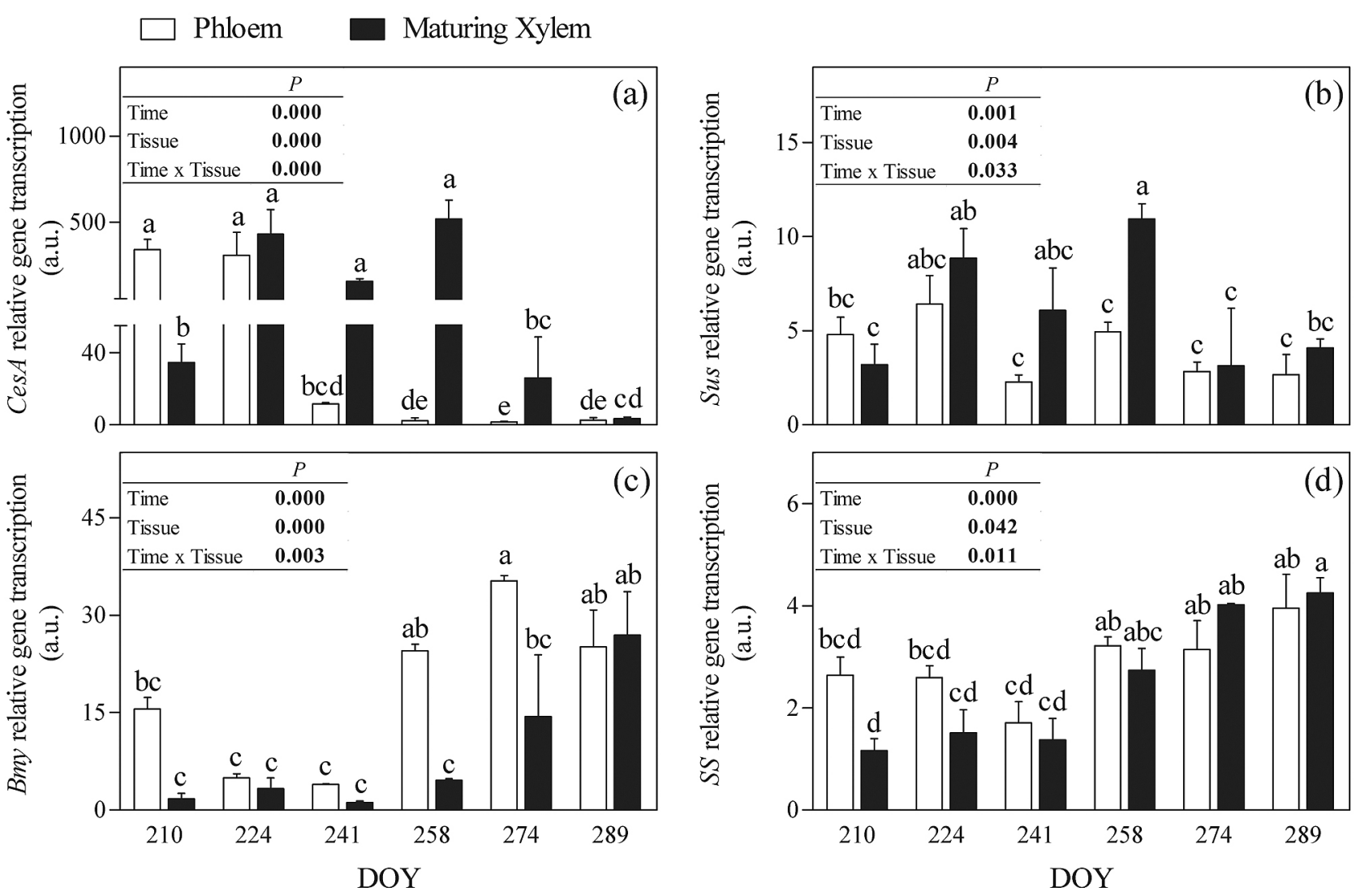

Fig. 4. mRNA transcriptional accumulations of $\alpha$-cellulose synthase - CesA (a), sucrose synthase - Sus (b), $\beta$-amylase - Bmy (c), and starch synthase - SS (d) genes in the Ph and the MXy during the growth to dormancy transition phase in Norway spruce stems. Bars represent the mean + SD. Two-way ANOVA P-values and Tukey-Kramer post hoc test results are reported in the figure. CesA mRNA transcriptional accumulation data were $\log _{10}(\mathrm{x})$ transformed in before the analysis

metabolism, cellulose metabolism and sucrose catabolism showed similar trends (Tab. S2 in Supplementary Materials). In fact, significant correlations occurred between Bmy and SS ( $\mathrm{R}=0.85, P<0.001)$, and Sus and CesA $(\mathrm{R}=0.93, P<0.001)$ mRNA levels in the MXy while lower correlations were recorded in the $\mathrm{Ph}$.

\section{Discussion}

The aim of this work was to investigate the pattern of carbohydrate changes during the growth to dormancy transition phase in the stem of Picea abies (L.) Karst, through a highly frequent sampling (interval sampling from 12 to 17 days). Results highlighted that the cambium dormancy did not affect the soluble carbohydrate concentrations in competing C-sinks, such as the $\mathrm{Ph}$ and $\mathrm{MXy}$, during the latewood formation. Our results further supported the idea that the arrest of the metabolic processes related to xylogenesis occurring during the transition to dormancy was not induced by a reduced C-availability within the main $\mathrm{C}$-sinks ( $\mathrm{Ph}$ and MXy), as already reported for cambial region in Picea abies (L.) Karst (Simard et al., 2013).
The level of sucrose in the Ph and MXy was never limiting DW during the latewood formation. This result supported the hypothesis that a basal concentration of sucrose within the sink, such as cambium, could be maintained over the season. On the other hand, glucose and fructose could accumulate in response to sucrose catabolism (Geiger, 2011; Ko et al., 2011). In Norway spruce, the cambium and its derivative cambial cells represented powerful C-sinks, as already shown in poplar (Schrader \& Sauter, 2002; Deslauriers et al., 2009), Picea mariana Mill. (Deslauriers et al., 2014), Larix decidua Mill. (Simard et al., 2013) and beech (Scartazza et al., 2015). Sucrose, glucose, and fructose concentrations did not change in the Ph and MXy from DOY 216 to 254, as also reported in cambial region of Picea abies (L.) Karst (Simard et al., 2013). On the contrary, glucose, fructose, and pinitol concentrations decreased significantly in the Xy during the latewood formation. These results did not confirm previous findings on Picea spp. showing that pinitol concentration did not change over the season within the xylem (Simard et al., 2013; Deslauriers et al., 2014). The variation in pinitol content could be due to a shift of this polyol from the storage compartment (living parenchyma within the xylem) towards the MXy and Ph to protect 
these compartments from the water stress damages as already shown in Norway spruce (Tomasella et al., 2017) and Douglas fir (Jansen et al., 2014).

Surprisingly, we did not find starch within the newly formed woody ring during the latewood formation. The accumulation of starch into the ray cells of sapwood during late summer has already been reported for five-year-old plants (Liu et al., 2004) as well as for adult trees of Norway spruce (Simard et al., 2013). The discrepancy of our results with the previous findings might be due to the source of samples used for the determination of starch. In our experiment, we collected only the woody ring formed during the current year. Thus, the absence of starch into the current year wood ring could reflect a reduced storage capacity of newly formed ray cells rather than starch absence in the stem.

The cambium proliferation phase (DOY 210) was characterized by a high concentration of soluble sugars in the Xy and a high transcription of genes related to starch metabolism (Bmy and SS) and cellulose synthesis (CesA and Sus) in the Ph. The high level of mRNA accumulation of CesA in the Ph from DOY 210 to 224 indicated the occurrence of high rates of cell wall biosynthesis in this sink. During this phenophase, the carbon used for the cell wall biosynthesis could be supplied by the sucrose derived from photosynthesis and loaded in the phloem rather than by the stored starch (low starch concentration as well as low Bmy mRNA accumulation). These results provide evidence that at least part of xyloglucan and cellulose in the stem could be synthesized from sucrose loaded directly into the phloem (Konishi et al., 2004). The mobilization of the soluble sugars and phenylpropanoid precursors from the phloem to the cambial region during summer has been already reported in Larix sibirica Ldb. (Antonova et al., 2008), Pinus sylvestris L. (Antonova et al., 2006), and Picea abies (L.) Karst (Emiliani et al., 2011). Furthermore, also the hexoses, glucose and fructose, in the Xy could be used to support the production of cellulose and lignin as highlighted by their lower value from DOY 224 to DOY 274, in correspondence with the high number of cells that have transitioned to wall thickening. The CesA-Sus gene down-regulation from DOY 274 was related to the end of cell wall thickening phase and to a metabolic shift toward the starch synthesis in both MXy and Ph. In particular, the down-regulation of the Ces $A$ was associated with an accumulation of starch in both tissues and a high transcription of Bmy and SS genes.

In Norway spruce during the cambium transition to dormancy the starch accumulation did not compete with cellulose biosynthesis for the carbon, as already reported in A. thaliana (Delmer et al., 2002) and oak (Hill et al., 1995). Thus, the down-regulation of the CesA and Sus in the MXy was related to the end of the secondary wall formation and it might represent a key signal that shift the carbon flux from utilization sinks toward the storage compartments within the stem. After the Ces $A$ down-regulation, the soluble sugars could be addressed to the starch accumulation and/or the phenylpropanoid metabolism for the latewood formation, as previously shown by Emiliani et al. (2011). Specifically, the homologue AtCesA7 gene in $A$. thaliana was associated with secondary cell wall development (Samuga \& Joshi, 2002). A direct role of CesA family genes in the cellulose biosynthesis was showed using $A$. thaliana (Persson et al., 2007; Bashline et al., 2014). Furthermore, the role of Sus in the modulation of C-sink strength has been demonstrated in different species such as poplar (Coleman et al., 2007), tobacco (Coleman et al., 2006), and sugarcane (Wang et al., 2013). The relative gene transcriptions of CesA and Sus were highly correlated in the MXy (Pearson's coefficient 0.93, $P$ $<0.001)$ confirming both genes probably belonged to the same catalytic unit (Coleman et al., 2009; Fujii et al., 2010). Surprisingly, CesA and Sus transcript accumulations were not correlated within the $\mathrm{Ph}$ (Pearson's coefficient 0.57, $P=0.055$ ). These results highlighted that the expression pattern of different CesA genes might be tissue-specific (Holland et al., 2000; Delmer et al., 2002) and then specific CesA isoforms could be activated in the Ph. Moreover, the asynchronous mRNA accumulation of CesA and Sus within the $\mathrm{Ph}$ and MXy could mirror the different C-sink strength of these tissues during the latewood formation. In particular, the down-regulation of the Ces $A$ gene in the $\mathrm{Ph}$ preceded by one month the down-regulation in the MXy highlighting that different timing and rates of sugar metabolism took place in these tissues. Since the amount of soluble carbohydrates within the MXy and $\mathrm{Ph}$ was never limiting during the experiment, the cessation of the CesA transcription was not induced by C-limitation or sink competition. Multiple external factors were known to control cell wall synthesis, such as circadian clock, light quality, and temperature (Ivakov et al., 2017). In particular, cellulose biosynthesis was considered a temperature-sensitive process and a night temperature $<22^{\circ} \mathrm{C}$ was defined as sub-optimal to maintain high rate of crystalline cellulose deposition in the secondary cell wall of cotton (Delmer et al., 2002). During the late summer-middle autumn, the temperature and the daylight duration decreased rapidly from DOY 274 to DOY 289 and the mean temperature in the nursery ranged between $18^{\circ} \mathrm{C}$ and $10^{\circ} \mathrm{C}$ (data reported in Emiliani et al., 2011). In this frame, cellulose biosynthesis might cease as a consequence of decreasing temperature or shortened photoperiod. The decrease of cellulose synthesis seemed to exert a genetic control over the starch metabolism in MXy. Furthermore, in this tissue, the increase of SS 
transcription was probably due to the necessity to accumulate starch for the reactivation of cambium during the following growing season, as also observed in Abies sachalinensis Schmidt. (Oribe et al., 2003). On the other hand, the decrease of temperature imposed the need to have starch-derived sugars acting as osmoprotectants or energy sources to achieve cold acclimation, as found also in Picea sitchensis (Dauwe et al., 2012). Thus, also the starch degradation (Bmy gene) increased as well as the amount of soluble sugars within the Xy.

On the basis of the results, the spatial and temporal patterns of the non-structural carbohydrate contents and the transcriptional accumulation of the genes involved in carbohydrate metabolism during latewood formation were highly related to the high C-requirement of maturing xylem and ray parenchyma while the dormant cambium did not represent a powerful C-sink at this stage. In particular, the pattern of soluble carbohydrate changes was modulated in the MXy by cellulose metabolism during the xylogenesis and by starch metabolism during the dormancy of cambium while the cellulose and starch metabolisms in the $\mathrm{Ph}$ did not seem to be related to wood formation.

\section{Aknowledgments}

The research was supported by Provincia Autonoma di Trento (Italy) to AG, project SOFIE-2 (Reg. Delib. No 3012-2007).

\section{References}

Antonova GF \& Stasova VV (2006) Seasonal development of phloem in Scots pine stems. Russian Journal of Developmental Biology 37: 306-320.

Antonova GF \& Stasova VV (2008) Seasonal development of phloem in Siberian larch stems. Russian Journal of Developmental Biology 39: 207-218.

Antonova GF, Varaksina TN, Zheleznichenko V \& Stasova VV (2014) Lignin deposition during earlywood and latewood formation in Scots pine stems. Wood Science and Technology 48: 919-936.

Babb VM \& Haigler CH (2001) Sucrose phosphate synthase activity rises in correlation with highrate cellulose synthesis in three heterotrophic systems. Plant Physiology 127: 1234-1242.

Balducci L, Cuny HE, Rathgeber CB, Deslauriers A, Giovannelli A \& Rossi S (2016) Compensatory mechanisms mitigate the effect of warming and drought on wood formation. Plant, Cell \& Environment 39: 1338-1352.

Bashline L, Li S \& Gu Y (2014) The trafficking of the cellulose synthase complex in higher plants. Annals of Botany 114: 1059-1067.
Begum S, Nakaba S, Oribe Y, Kubo T \& Funada R (2010) Changes in the localization and levels of starch and lipids in cambium and phloem during cambial reactivation by artificial heating of main stems of Cryptomeria japonica trees. Annals of Botany 106: 885-895.

Björklund J, Seftigen K, Schweingruber F, Fonti P, Arx G, Bryukhanova MV, Cuny HE, Carrer M, Castagneri D \& Frank DC (2017) Cell size and wall dimensions drive distinct variability of earlywood and latewood density in Northern Hemisphere conifers. New Phytologist 216: 728-740.

Boerjan W, Ralph J \& Baucher M (2003) Lignin biosynthesis. Annual Review of Plant Biology 54: 519-546.

Castagneri D, Fonti P, Von Arx G \& Carrer M (2017) How does climate influence xylem morphogenesis over the growing season? Insights from longterm intra-ring anatomy in Picea abies. Annals of Botany 19: 1011-1020.

Chang S, Puryear J \& Cairney J (1993) A simple and efficient method for isolating RNA from pine trees. Plant Molecular Biology Reporter 11: 113116.

Coleman HD, Canam T, Kang KY, Ellis DD \& Mansfield SD (2007) Over-expression of UDP-glucose pyrophosphorylase in hybrid poplar affects carbon allocation. Journal of Experimental Botany 58: 4257-4268.

Coleman HD, Ellis DD, Gilbert M \& Mansfield SD (2006) Up-regulation of sucrose synthase and UDP-glucose pyrophosphorylase impacts plant growth and metabolism. Plant Biotechnology Journal 4: 87-101.

Coleman HD, Yan J \& Mansfield SD (2009) Sucrose synthase affects carbon partitioning to increase cellulose production and altered cell wall ultrastructure. Proceedings of the National Academy of Sciences 106: 13118-13123.

Dauwe R, Holliday JA, Aitken SN \& Mansfield SD (2012) Metabolic dynamics during autumn cold acclimation within and among populations of Sitka spruce (Picea sitchensis). New Phytologist 194: 192-205.

Delmer DP \& Haigler CH (2002) The regulation of metabolic flux to cellulose, a major sink for carbon in plants. Metabolic Engineering 4: 22-28.

Deslauriers A, Beaulieu M, Balducci L, Giovannelli A, Gagnon MJ \& Rossi S (2014) Impact of warming and drought on carbon balance related to wood formation in black spruce. Annals of Botany 114: 335-345.

Deslauriers A, Giovannelli A, Rossi S, Castro G, Fragnelli G \& Traversi L (2009) Intra-annual cambial activity and carbon availability in stem of poplar. Tree Physiology 29: 1223-1235. 
Dickson RE (1989) Carbon and nitrogen allocation in trees. Annales des Sciences Forestieres 46: 631-647.

Emiliani G, Traversi ML, Anichini M, Giachi G \& Giovannelli A (2011) Transcript accumulation dynamics of phenylpropanoid pathway genes in the maturing xylem and phloem of Picea abies during latewood formation. Journal of Integrative Plant Biology 53: 783-799.

Fujii S, Hayashi T \& Mizuno K (2010) Sucrose synthase is an integral component of the cellulose synthesis machinery. Plant and Cell Physiology 51: 294-301.

Geiger D (2011) Plant sucrose transporters from a biophysical point of view. Molecular Plant 4: 395406.

Geisler-Lee J, Geisler M, Coutinho PM, Segerman B, Nishikubo N, Takahashi J, Aspeborg H, Djerbi S, Master E, Andersson-Gunnerås S, Sundberg B, Karpinski S, Teeri TT, Kleczkowski LA, Henrissat B \& Mellerowicz EJ (2006) Poplar carbohydrate-active enzymes. Gene identification and expression analyses. Plant Physiology 140: 946-962.

Gindl W, Grabner M \& Wimmer R (2000) The influence of temperature on latewood lignin content in treeline Norway spruce compared with maximum density and ring width. Trees 14: 409-414.

Giovannelli A, Emiliani G, Traversi ML, Deslauriers A \& Rossi S (2011) Sampling cambial region and mature xylem for non structural carbohydrates and starch analyses. Dendrochronologia 29: 177182.

Gruber A, Pirkebner D \& Oberhuber W (2013) Seasonal dynamics of mobile carbohydrate pools in phloem and xylem of two alpine timberline conifers. Tree Physiology 33: 1076-1083.

Harris DC (1997) Internal standards: Quantitative chemical analysis. 5th ed. New York, W. H. Freeman and Company 104.

Hill SA, Waterhouse JS, Field EM, Switsur VR \& Ap Rees T (1995) Rapid recycling of triose phosphates in oak stem tissue. Plant, Cell \& Environment 18: 931-936.

Hoch G, Richter A \& Körner C (2003) Non-structural carbon compounds in temperate forest trees. Plant, Cell \& Environment 26: 1067-1081.

Holland N, Holland D, Helentjaris T, Dhugga KS, Xoconostle-Cazares B \& Delmer DP (2000) A comparative analysis of the plant cellulose synthase (CesA) gene family. Plant Physiology 123: 1313-1323.

Huala E, Dickerman AW, Garcia-Hernandez M, Weems D, Reiser L, LaFond F, Hanley D, Kiphart D, Zhuang M, Huang W, Mueller LA, Bhattacharyya $D$, Bhaya $D$, Sobral BW, Beavis W, Meinke DW, Town CD, Somerville C \& Rhee SY (2001) The Arabidopsis Information Resource (TAIR): a comprehensive database and web-based information retrieval, analysis, and visualization system for a model plant. Nucleic Acids Research 29: 102-105.

Ivakov A, Flis A, Apelt F, Fuenfgeld M, Scherer U, Stitt M, Kragler F, Vissenberg K, Persson S \& Suslov D (2017) Cellulose synthesis and cell expansion are regulated by different mechanisms in growing Arabidopsis hypocotyls. Plant Cell 29: 1305-1315.

Jansen K, Du B, Kayler Z, Siegwolf R, Ensminger I, Rennenberg H, Kammerer B, Jaeger C, Schaub M, Kreuzwieser J \& Gessler A (2014) Douglas-fir seedlings exhibit metabolic responses to increased temperature and atmospheric drought. PloS One 9: e114165.

Jyske TM, Suuronen JP, Pranovich AV, Laakso T, Watanabe U, Kuroda K \& Abe H (2015) Seasonal variation in formation, structure, and chemical properties of phloem in Picea abies as studied by novel microtechniques. Planta 242: 613-629.

Ko JH, Prassinos C, Keathley D \& Han KH (2011) Novel aspects of transcriptional regulation in the winter survival and maintenance mechanism of poplar. Tree Physiology 31: 208-225.

Konishi T, Ohmiya Y \& Hayashi T (2004) Evidence that sucrose loaded into the phloem of a poplar leaf is used directly by sucrose synthase associated with various $\beta$-glucan synthases in the stem. Plant Physiology 134: 1146-1152.

Liu X, Kozovits AR, Grams TEE, Blaschke H, Rennenberg H \& Matyssek R (2004) Competition modifies effects of enhanced ozone/carbon dioxide concentration on carbohydrate and biomass accumulation in juvenile Norway spruce and European beech. Tree Physiology 24: 1045-1055.

Loescher WH, McCamant T \& Keller JD (1990) Carbohydrate reserves, translocation, and storage in woody plant roots. Horticultural Science 25: 274-281.

Magel EA, Hillinger C, Höll W \& Ziegler H (1997) Biochemistry and physiology of heartwood formation: role of reserve substances: Trees - Contribution to modern tree physiology (ed. by H Rennenberg, W Eschrich, H. Ziegler) SFB Academic publisher, The Hague, pp. 257-270.

Nystedt B, Street NR, Wetterbom A, Zuccolo A, Lin YC, Scofield DG, Vezzi F, Delhomme N, Giacomello S, Alexeyenko A, Vicedomini R, Sahlin K, Sherwood E, Elfstrand M, Gramzow L, Holmberg K, Hällman J, Keech O, Klasson L, Koriabine M, Kucukoglu M, Käller M, Luthman J, Lysholm F, Niittylä T, Olson A, Rilakovic N, Ritland C, Rosselló JA, Sena J, Svensson T, Talavera-Lòpez C, Theißen G, Tuominen H, Vanneste K, Wu ZQ, Zhang B, Zerbe P, Arvestad L, Bhalerao R, Bohlmann J, Bousquet J, Gil RG, Hvidsten TR, De Jong 
P, MacKay J, Morgante M, Ritland K, Sundberg B, Thompson SL, Van de Peer Y, Andersson B, Nilsson $\mathrm{O}$, Ingvarsson PK, Lundeberg J \& Jansson S (2013) The Norway spruce genome sequence and conifer genome evolution. Nature 497: 579-584.

Oribe Y, Funada R \& Kubo T (2003) Relationships between cambial activity, cell differentiation and the localization of starch in storage tissues around the cambium in locally heated stems of Abies sachalinensis (Schmidt) Masters. Trees-Structure and Function 17: 185-192.

Persson S, Paredez A, Carroll A, Palsdottir H, Doblin M, Poindexter P, Khitrov N, Auer M \& Somerville CR (2007) Genetic evidence for three unique components in primary cell-wall cellulose synthase complexes in Arabidopsis. Proceedings of the National Academy of Sciences 104: 15566-15571.

Rathgeber CBK, Cuny HE \& Fonti P (2016) Biological basis of tree-ring formation: a crash course. Frontiers in Plant Science 7: 734.

Regier N, Streb S, Zeeman SC \& Frey B (2010) Seasonal changes in starch and sugar content of poplar (Populus deltoides x nigra cv. Dorskamp) and the impact of stem girdling on carbohydrate allocation to roots. Tree Physiology 30: 979-987.

Ruan YL (2014) Sucrose metabolism: gateway to diverse carbon use and sugar signaling. Annual Review of Plant Biology 65: 33-67.

Sala A, Woodruff DR \& Meinzer FC (2012) Carbon dynamics in trees: feast or famine? Tree Physiology 32: 764-775.

Samuga A \& Joshi CP (2002) A new cellulose synthase gene (PtrCesA2) from aspen xylem is orthologous to Arabidopsis AtCesA (irx3) gene associated with secondary cell wall synthesis. Gene 296: 37-44.

Scartazza A, Moscatello S, Matteucci G, Battistelli A \& Brugnoli E (2015) Combining stable isotope and carbohydrate analyses in phloem sap and fine roots to study seasonal changes of source-sink relationships in a Mediterranean beech forest. Tree Physiology 35: 829-839.
Schrader S \& Sauter JJ (2002) Seasonal changes of sucrose-phosphate synthase and sucrose synthase activities in poplar wood (Populus $\times$ canadensis Moench (robusta) and their possible role in carbohydrate metabolism. Journal of Plant Physiology 159: 833-843.

Sharkey TD (2015) Understanding carbon partitioning and its role in determining plant growth. Plant, Cell \& Environment 38: 1963-1964.

Simard S, Giovannelli A, Treydte K, Traversi ML, King GM, Frank D \& Fonti P (2013) Intra-annual dynamics of non-structural carbohydrates in the cambium of mature conifer trees reflects radial growth demands. Tree Physiology 33: 913-923.

Sonnewald U \& Willmitzer L (1992) Molecular approaches to sink-source interactions. Plant Physiology 99: 1267-1270.

Stitt M \& Zeeman SC (2012) Starch turnover: pathways, regulation and role in growth. Current Opinion in Plant Biology 15: 282-292.

Tomasella M, Häberle KH, Nardini A, Hesse B, Machlet A \& Matyssek R (2017) Post-drought hydraulic recovery is accompanied by non-structural carbohydrate depletion in the stem wood of Norway spruce saplings. Scientific Reports 7: 14308.

Uggla C, Magel E, Moritz T \& Sundberg B (2001) Function and dynamics of auxin and carbohydrates during earlywood/latewood transition in Scots pine. Plant Physiology 125: 2029-2039.

Wang J, Nayak S, Koch K \& Ming R (2013) Carbon partitioning in sugarcane (Saccharum species). Frontiers in Plant Science 4: 201.

Wardlaw IF (1990) Tansley Review No. 27 The control of carbon partitioning in plants. New Phytologist 116: 341-381.

Wimmer R (1995) Intra-annual cellular characteristics and their implications for modelling softwood density. Wood and Fiber Science 27: 413-420.

Witt W \& Sauter JJ (1994) Starch metabolism in poplar wood ray cells during spring mobilization and summer deposition. Physiologia Plantarum 92: 9-16. 